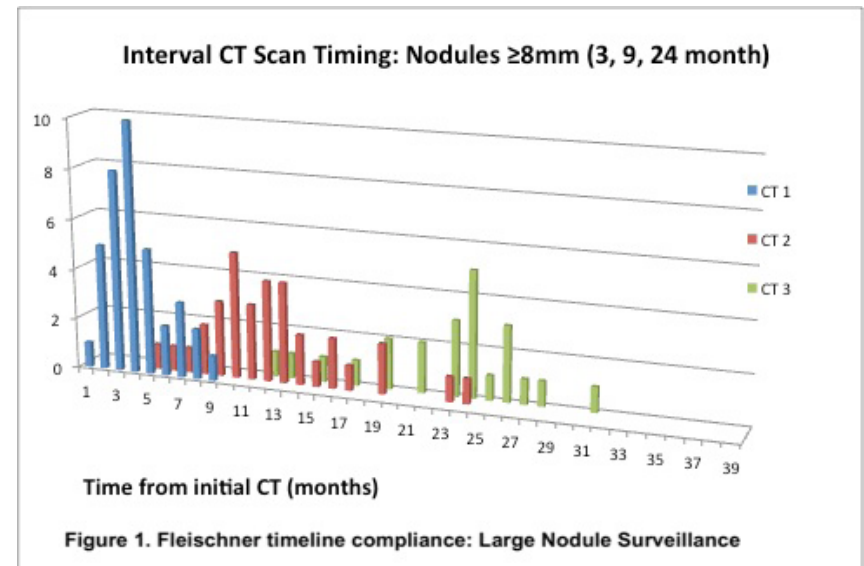

Abstract P195 Figure 1

\section{P196 PERCUTANEOUS ULTRASOUND-GUIDED BIOPSY OF INTRATHORACIC PARIETAL MASSES - A SAFE ALTERNATIVE TO CT-GUIDED BIOPSY?}

doi:10.1136/thoraxjnl-2012-202678.257

TRG Simpson, G Constantinescu, P Mellor, S Lohani, B Khan, M Mushtaq, I Abdelhadi, B Bhattacharjee, V Serafimov. Darent Valley Hospital, Dartford and Gravesham NHS Trust, Dartford, UK

Background The current gold standard method for sampling intrathoracic lesions is via a CT-guided approach. However, most parietal-attached intrathoracic lesions can be visualised with ultrasound and sampled.

Aims A prospective audit of consecutive patients with CT-identified intrathoracic parietal-attached lesions, sampled percutaneously by an ultrasound-guided approach, was carried out to assess efficacy and safety. The lung MDT was instrumental in selecting patients.

Materials and Methods Seventeen consecutive patients were audited over a span of 8 months. This cohort included 12 males and 5 females with an age range from 42 to 84 years (median 63 years). The biopsies were performed by 4 skilled investigators assisted by a specialist nurse, using an 18 gauge single-trochar puncture under standard aseptic conditions. A Toshiba Applio ultrasound unit, with Doppler-flow map capabilities was used to avoid vessel puncture. Patients recovered in the radiology department observation ward.

Results Interpretable specimens were obtained in 16 patients. A single patient needed a repeat, successful, US-guided procedure. The median duration for the procedure was 26 minutes, with a median observation time before discharge of a further 40 minutes. Two patients developed small pneumothoraces and one patient suffered minor haemoptysis, none of which required admission.

Conclusion Where applicable, this technique is safe, fast, avoids radiation and may result in fewer complications compared to the CTguided approach. Fewer personnel are required and CT scanner time is freed for other uses. Moreover, in the hands of an ultrasound-skilled respiratory physician, this method correctly applied would provide an earlier route to diagnosis for the Lung MDT.

\section{P197 OBTAINING A TISSUE DIAGNOSIS IN LUNG CANCER PATIENTS WITH POOR PERFORMANCE STATUS MAY NOT INFLUENCE TREATMENT OR CONFER SURVIVAL BENEFIT}

doi:10.1136/thoraxjnl-2012-202678.258

1JD Maclay, ${ }^{2} \mathrm{~J}$ Farley, ${ }^{1} \mathrm{C}$ Tweed, ${ }^{3} \mathrm{~J}$ van der Horst, ${ }^{4} \mathrm{~S}$ Bicknell, ${ }^{1 R}$ Milroy. ${ }^{1}$ Glasgow Royal Infirmary \& Stobhill Hospital, Glasgow, UK; ${ }^{2}$ Stobhill Hospital, Glasgow, UK; ${ }^{3}$ Glasgow Royal Infirmary, Glasgow, UK; ${ }^{4}$ Gartnavel General Hospital, Glasgow, UK

Introduction Further investigation and treatment following a radiological diagnosis of lung cancer is influenced by the fitness of a patient. A pragmatic approach to investigative procedures is often adopted based on the risks and benefits. Another consideration is whether tissue diagnosis is necessary for anticipated future treatment. Tissue diagnosis is usually deemed essential prior to administration of radical radiotherapy and chemotherapy, but less so for palliative radiotherapy. Methods All patients with lung cancer diagnosed in North Glasgow in 2009 and 2010 were prospectively recorded in a registry. We subsequently investigated the relationships between WHO performance status (PS) and tissue diagnosis, treatment and survival. Patients were followed up for at least 18 months after entry into the registry. Results 1190 patients were diagnosed with lung cancer during the study period and clinical details were recorded at a multidisciplinary meeting. PS was recorded in $91 \%$.

Overall, tissue diagnosis was achieved in $76 \%$ of patients. Tissue diagnosis was achieved in $98 \%$ of patients with PS 0 following diagnostic procedure or surgery (table 1 ). Nearly $90 \%$ of these patients underwent chemotherapy, surgery or radical radiotherapy.

Tissue diagnosis was attempted in $71 \%$ and $46 \%$ of PS 3 and 4 respectively. Of these patients, treatment was influenced by tissue diagnosis in $15 \%$ and $0 \%$. Survival was compared in these patients and there was no difference between patients with a PS of 3 or 4 that had tissue diagnosis attempted and those that did not (median days (interquartile range); PS3: tissue 53 (19-138) vs no tissue 59 (17-156); PS4: 18 (8-36) vs 16 (6-32)).

Conclusions A significant percentage of patients with performance status 3 and 4 undergo diagnostic tests to establish a tissue diagnosis. However, treatment is only influenced by this in a minority of cases. Considering likely future treatment is important when pursuing a tissue diagnosis in these patients. In addition, attempting tissue diagnosis in these patients did not confer any survival benefit.

\section{P198 TEN YEAR FOLLOW UP OF MESOTHELIOMA IN NORTH YORKSHIRE}

doi:10.1136/thoraxjnl-2012-202678.259

R Smith, AK Datta. York Teaching Hospital, Hull York Medical School, York, UK

All 123 malignant mesothelioma patients in York and North Yorkshire between 2002-2011 were analysed from Cancer Registry and

Abstract P197 Table 1

\begin{tabular}{|c|c|c|c|c|c|c|}
\hline & 0 & 1 & 2 & 3 & 4 & Not recorded \\
\hline$n$ & 132 & 381 & 336 & 186 & 48 & 107 \\
\hline Tissue diagnosis attempted, n (\%) & $126(96)$ & $355(93)$ & $300(89)$ & $132(71)$ & $22(46)$ & $59(55)$ \\
\hline Tissue diagnosis achieved* ${ }^{*} \mathrm{n}(\%)$ & $129(98)$ & $358(94)$ & $278(83)$ & $118(63)$ & $17(35)$ & $55(51)$ \\
\hline \multicolumn{7}{|l|}{ Treatment, n (\%) } \\
\hline Best supportive care & $4(3)$ & $29(8)$ & $68(25)$ & $65(55)$ & $14(82)$ & $22(40)$ \\
\hline Palliative XRT & $11(9)$ & $82(23)$ & $91(33)$ & $36(31)$ & $3(18)$ & $17(31)$ \\
\hline Chemotherapy & $66(51)$ & $133(37)$ & $86(31)$ & $15(13)$ & $0(0)$ & $9(16)$ \\
\hline Surgery or radical XRT & $48(37)$ & $114(32)$ & $33(12)$ & $2(2)$ & $0(0)$ & $7(13)$ \\
\hline
\end{tabular}

*Some patients had tissue diagnosis following a surgical procedure. 